\title{
Self-assembled Viral Nanoparticles as Targeted Anticancer Vehicles
}

\author{
Yuanzheng Wu, Jishun Li, and Hyun-Jae Shin
}

Received: 8 December 2020 / Revised: 4 January 2021 / Accepted: 6 January 2021

(C) The Korean Society for Biotechnology and Bioengineering and Springer 2021

\begin{abstract}
Viral nanoparticles (VNPs) comprise a variety of mammalian viruses, plant viruses, and bacteriophages, that have been adopted as building blocks and supramolecular templates in nanotechnology. VNPs demonstrate the dynamic, monodisperse, polyvalent, and symmetrical architectures which represent examples of such biological templates. These programmable scaffolds have been exploited for genetic and chemical manipulation for displaying of targeted moieties together with encapsulation of various payloads for diagnosis or therapeutic intervention. The drug delivery system based on VNPs offer diverse advantages over synthetic nanoparticles, including biocompatibility, biodegradability, water solubility, and high uptake capability. Here we summarize the recent progress of VNPs especially as targeted anticancer vehicles from the encapsulation and surface modification mechanisms, involved viruses and VNPs, to their application potentials.
\end{abstract}

Keywords: viral nanoparticles (VNPs), self-assembly, anticancer, drug delivery, nanotechnology

\section{Introduction}

Recent advances in nanotechnology have facilitated the development of medical science, especially in the field of drug delivery for therapeutic and/or imaging applications [1]. Numerous nanomaterials have been investigated for

Yuanzheng Wu, Jishun Li

Ecology Institute, Qilu University of Technology (Shandong Academy of Sciences), Shandong Provincial Key Laboratory of Applied Microbiology, Jinan 250103, China

Hyun-Jae Shin*

Department of Biochemical and Polymer Engineering, Chosun University, Gwangju 61452, Korea

Tel: +82-62-230-7518, Fax: +82-62-230-7226

E-mail: shinhj@chosun.ac.kr their potentials as drug carriers, including liposomes, polymers, dendrimers, inorganic nanoparticles, and proteinbased nanoparticles [2-4]. Nanoparticles (NPs) for drug delivery systems are capable of carrying large quantities of therapeutics, targeting particular cells of interest, and presenting sufficient physiochemical properties $[5,6]$. However, some of these synthetic carriers are limited by their biocompatibility, toxicity, and/or low efficiency for clinical utilization [7].

Viral nanoparticles (VNPs) are virus-derived formulations of protein-polynucleotides hybridized supramolecular assemblies that can be adopted as building blocks and templates due to their sophisticated architectures [8]. The essential nature of viruses is to infect a host cell, replicate, package its nucleic acid, and exit the cell, during which they display the exceptional plasticity of dynamic, selfassembled systems with precise dimensions and monodisperse structures [9]. VNPs include bacteriophages, plant and animal viruses, with a distinctive diversity of shapes (icosahedral, helical, enveloped, or complex) and a variety of sizes (from tens to hundreds of nanometers) [10]. Viruslike particles (VLPs) are a subset of VNPs consisted of multiple protein subunits without genomic materials that makes them noninfectious and unable to replicate [11]. VLPs and VNPs can be produced on large scale in short time either from natural infected tissues or heterologous expression systems. These protein-based nanoparticles possess numerous advantages over other synthetic NPs, such as water solubility, immune evasion, biocompatibility, and bioavailability $[12,13]$.

VNPs present "programmable" scaffolds because the viral protein cages can be modified both chemically and genetically to load therapeutic cargoes and install targeting ligands $[14,15]$. Chemical modification and genetic manipulation on the outer surfaces and inner cavities of VNPs have been employed for the construction of multivalent 
and multifunctional viral capsid-based materials $[16,17]$. VNPs are remarkably stable and robust to endure the pressure and degradation in the cellular environment, meanwhile they are sensitive to recognize signals and release payloads when instructed [18]. This flexibility confers them suitable tolls for material science and pharmaceutics research.

Various VNPs have been extensively studied for targeted delivery and imaging potentials due to their capability of transfection, e.g. cowpea mosaic virus (CPMV), cowpea chlorotic mottle virus (CCMV), tobacco mosaic virus (TMV), and bacteriophages such as MS2, P22, and Q $\beta$ [19-23]. Viral vectors derived from adenovirus (Ad), adenoassociated virus (AAV), herpes simplex virus (HSV), and other oncolytic viruses have also been widely used as gene delivery vehicles and even clinically approved vaccines [24-26]. In this review, we focus on the recent progress of VNPs as targeted anticancer vehicles including their encapsulation and surface modification mechanisms, the involved viruses and VNPs, and their application potentials.

\section{Encapsulation and Surface Modification Mechanisms by VNPs}

VNPs are flexible and amenable for packaging and delivering a broad range of cargoes such as nucleic acids, proteins, polymers, and chemotherapeutic drugs [27,28]. The interior interface of VNPs can be used to encapsulate, diffuse, absorb, or conjugate functional payloads and the exterior surface can also be decorated by multiple targeting moieties [29].

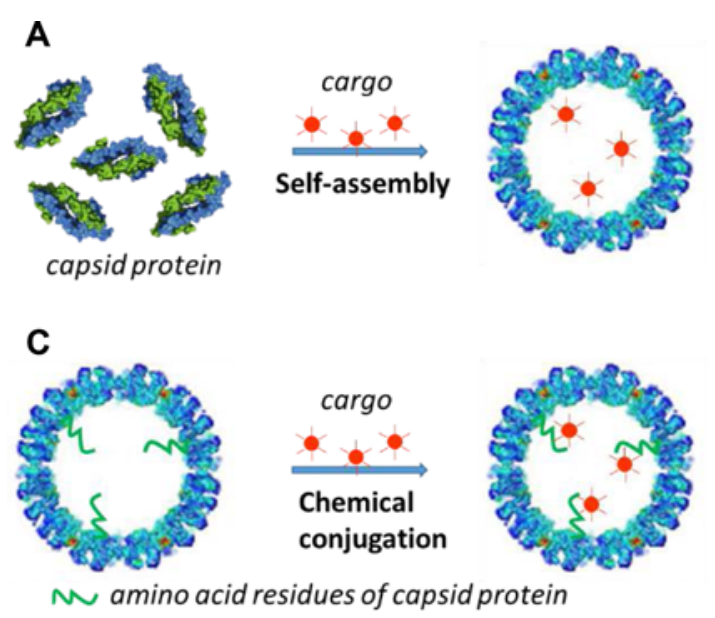

\subsection{Encapsulation by VNPs}

As shown in Fig. 1, different strategies such as selfassembly, diffusion, chemical conjugation, and genetic manipulation have been explored for loading cargoes inside the viral capsids. The genomic materials are generally packaged within the capsids by a reversible disassembly and reassembly process in vivo, and the principle regulating this process can be utilized for loading other cargoes [30]. Electrostatic interaction serves as the thermodynamic force driving efficient packaging and assembly of negatively charged molecules inside the positively charged interior surfaces of the capsids [31]. Bancroft et al. first revealed the encapsulation of polyanions instead of viral RNA by CCMV capsids, which was triggered by mixing the capsid protein subunits with functional cargoes at specific buffer conditions, ionic strength, temperature, and $\mathrm{pH}$ ranges in vitro $[32,33]$. As a model plant virus, CCMV has been widely studied by researchers for the capability to encapsulate various materials [34-36]. CCMV capsids can disassemble into protein dimers and release loaded cargoes at physiological $\mathrm{pH}$ or high ionic strength $(I \sim 1 \mathrm{M})$, and reassemble as the capsids when adjusting the buffer $\mathrm{pH}$ between 3 and 6 under low ionic strength $(I \sim 0.1 \mathrm{M})$ [37]. Taking advantage of this process, anionic polyoxometalate, negatively charged polyelectrolytes, and silencing RNA (siRNA) have been successfully encapsulated into CCMV capsids with potential pharmaceutical applications [38,39].

Interestingly, CCMV capsids expand into a "swollen state" with $10 \%$ radially larger and 60 open pores of ca. 2 $\mathrm{nm}$ on the cage at $\mathrm{pH} 5 \sim 6.5$ and $I \sim 0.1 \mathrm{M}$ [40]. Small molecules can diffuse freely into and out of the cavity with conditions changed, that provides a particular molecular

B
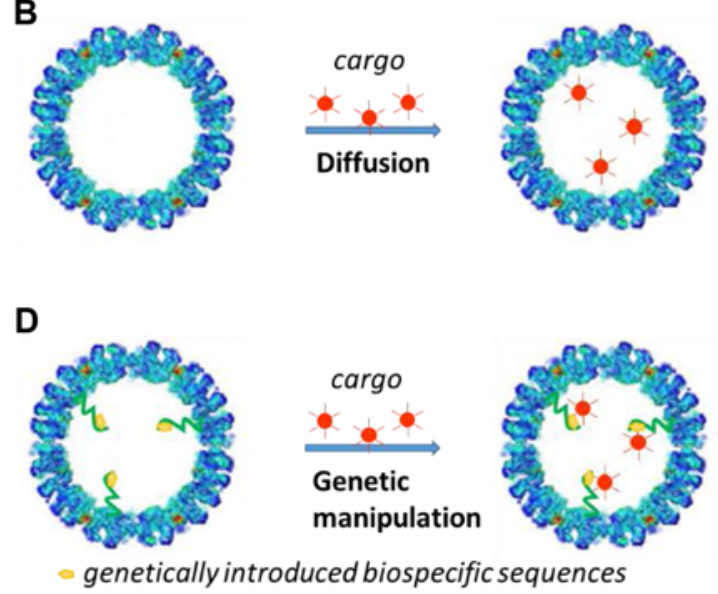

Fig. 1. Schematic diagram of the encapsulation mechanisms by viral nanoparticles to load cargoes. (A) Self-assembly around cargoes driven by electrostatic interaction under different $\mathrm{pH}$ and buffer conditions. (B) Diffusion of cargoes within viral capsids through open pores or channels due to altering $\mathrm{pH}$ and salt concentrations. (C) Chemical conjugation between the amino acid residues of capsid protein subunit and cargo moieties. (D) Genetic manipulation to introduce biospecific sequences for covalent attachment with cargo moieties. 
gating mechanism for the encapsulation and release of functional cargoes [41]. Similar open channels of 11 13 $\AA$ diameter are also formed by red clover necrotic mosaic virus (RCNMV) capsids with the removal of calcium and magnesium ions from the buffer, and the supplementation of these ions closes the formed channels [19]. By passive diffusion through these channels, doxorubicin (DOX) was loaded inside RCNMV capsids that were conjugated with a CD46-targeting peptide, which then showed significant cytotoxicity to HeLa cells in vitro [42].

In addition, chemical conjugation can be employed to encapsidate cargo molecules inside the capsids by covalent bond between the carboxylate groups of amino acid residues and the amine groups of cargo molecules [43]. The well-defined viral cavity offers the circumstance for cargo loading and synthesis inside the capsids [44]. For instance, the encapsidation of DOX by the major structural protein VP6 of rotavirus was accomplished through the amide bond between the carboxyl group of VP6 and the amine group of DOX [45]. The targeting moiety of lactobionic acid for hepatocytes or hepatoma cells bearing asialoglycoprotein receptors (ASGPRs) was then conjugated onto DOX-loaded VLPs, which exhibited immunofluorescence in human hepatocellular carcinomas (HepG2) cells in vitro. Building of similar strategy, cytosine deaminase and purine-nucleoside phosphorylase, two prodrug-converting enzymes, were tagged with a positively charged Rev peptide and encapsidated by bacteriophage $\mathrm{Q} \beta$ fused with a bifunctional linker RNA (biRNA) that recruits Rev-tagged cargo via noncovalent attachment of biRNA with capsid protein and Rev peptide [46].

Genetic manipulation provides another approach for the directed loading of cargoes by VNPs [47]. The cargo and capsid protein can be genetically manipulated separately or simultaneously to introduce biospecific sequences for covalent attachment with each other [48]. CCMV capsid protein and enhanced green fluorescent protein (EGFP) were fusion-expressed with the heterodimeric coiled-coil linkers of K-coil (KIAALKE) $)_{3}$ and E-coil (EIAALEK) $)_{3}$, respectively [49]. The in vitro assembly of EGFP-packaged capsids were achieved by specific heterodimerization between K-coil and E-coil. Making use of biotin/streptavidin affinity, the scaffolding proteins of bacteriophage P22 procapsids were genetically modified with streptavidin and biotin-4-fluorescein was then encapsulated via biotin/ streptavidin linker [50].

\subsection{Surface modification of VNPs}

Besides the strategies of encapsulation, VNPs can also integrate cargo molecules on the exterior surface of the capsids through bioconjugation with exposed amino acid residues (Fig. 2) [51]. The amino acid residues have been

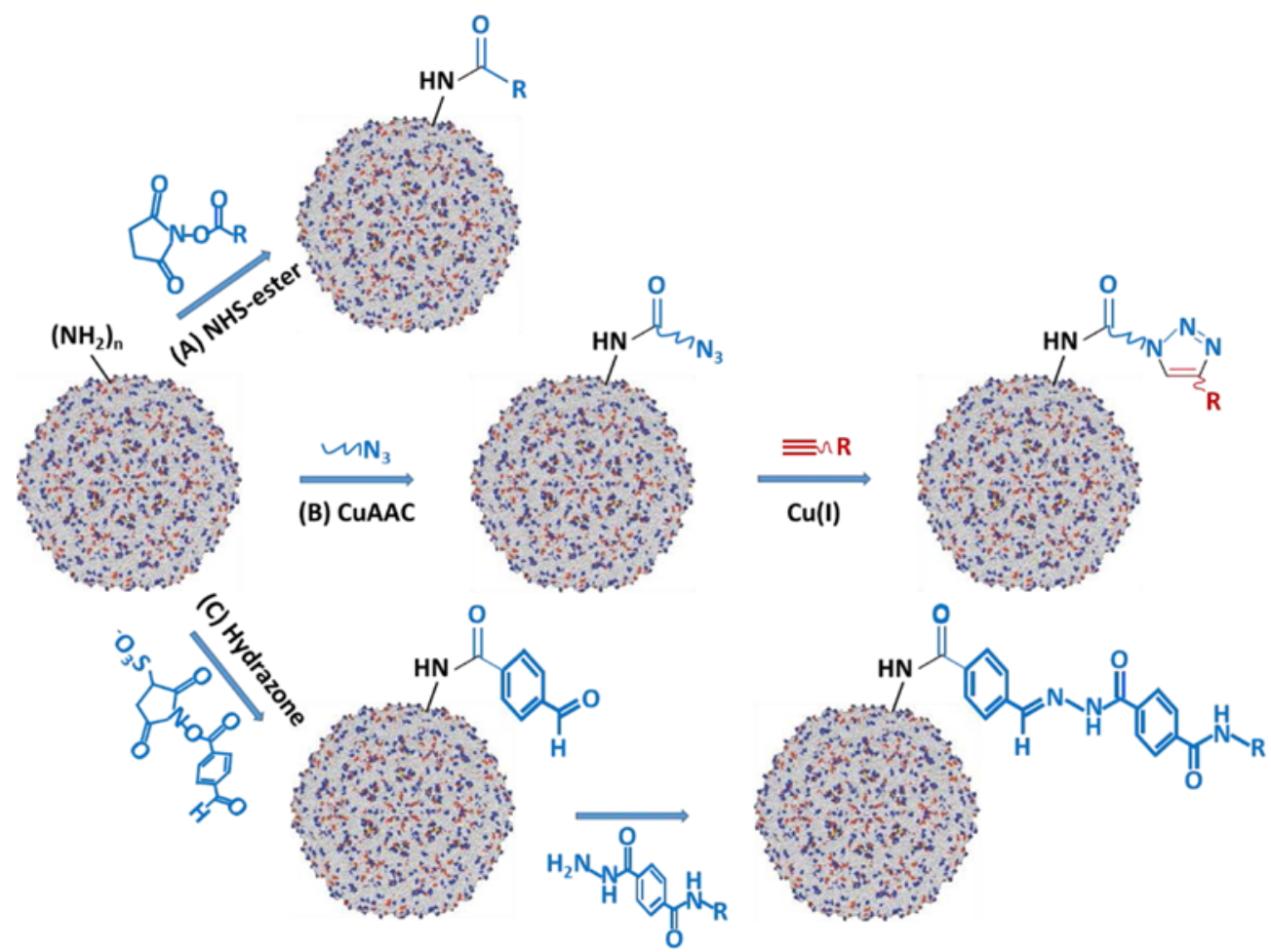

Fig. 2. Schematic diagram of the conjugation mechanisms on the exterior surface of the capsids of VNPs through bioconjugation to load cargoes. (A) NHS (N-hydroxysuccinimide) esters acylation. (B) Copper(I)-catalyzed azide-alkyne cycloaddition (CuAAC) reaction. (C) Hydrazone ligation. 
illustrated to be applicable and addressable by click chemistries, including endogenous amino acids such as lysines, glutamic or aspartic acids, and tyrosines, and genetically introduced ones such as cysteines [52,53].

NHS (N-hydroxysuccinimide) esters acylation is the simplest and most common technique used for surface modification of exposed amines, which involves carbodiimide crosslinking of carboxylates $(-\mathrm{COOH})$ with primary amines $\left(-\mathrm{NH}_{2}\right)$ [54]. Wang et al. first demonstrated NHSesters of fluorescein or biotin to conjugate with CPMV, and the obtaining VLPs showed a similar structure with selfassembled dendrimers or metallic NPs [55]. Varieties of reactive residues including tyrosines, carboxylate groups, natural and genetically introduced cysteines and histidine tags were decorated with small fluorescence molecules and peptides [56].

Copper(I)-catalyzed azide-alkyne cycloaddition (CuAAC) reaction has resulted in numerous applications in chemoselective ligation on virus surfaces since its first report in 2002 [57]. The azide and alkyne moiety can be attached to the desired cargo molecules and lysine, cysteine, or tyrosine residues on the surface of VNPs, respectively [58]. The selective reactivity between azide and alkyne groups makes CuAAC reaction more efficient with a notably lower molar excess of substrates compared with NHS-ester based chemistry [59]. CPMV was first exploited for the grafting of small fluorescent molecules via CuAAC reaction [60]. A mutant CPMV conjugated with the folic acid- polyethylene glycol (PEG) ligand showed specific recognition and binding with the folate receptor of tumour cells while complete elimination with normal cells [61]. Our

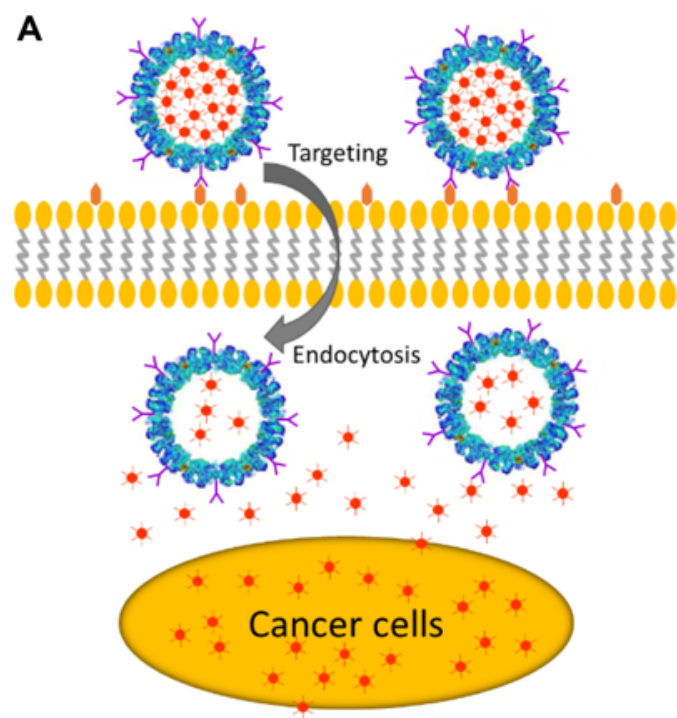

group also employed $\mathrm{CuAAC}$ reaction for the attachment of oligo-ethylene glycol short chain and Arg-Gly-Asp (RGD) peptide on the exterior surface of CCMV, resulting in opposite adhesion behaviors with HeLa cells [62].

Hydrazone ligation provides another chemoselective strategy for bioconjugation of VNPs with ligands under relatively less stable conditions. Benzaldehyde is first introduced to VNPs and then reacted with cargo molecules equipped with a hydrazido group via hydrazone ligation [63]. CPMV was assembled with individually tunable levels of vascular endothelial growth factor receptor (VEGFR) 1 ligand and fluorescent PEGylated peptide using this approach, which recognized VEGFR1 both in endothelial cell lines and tumour xenografted mice [64].

Although NHS esters acylation is simple, the yield and efficiency is not high compared to other bioconjugation reactions. CuAAC reaction is therefore preferred for its bioorthogonal, quicker and more readily proceeds than NHS or maleimide reactions. Hydrazone ligation is chemoselective and shows an absorbance near $350 \mathrm{~nm}$, which can be utilized VNPs conjugation when not stable in click chemistry reaction.

\section{Viral Nanoparticles for Cancer Therapy}

As illustrated in Fig. 3, a variety of viruses and VNPs exhibit the ability to carry the active drugs to cancer cells utilizing the unique pathophysiology of tumors, such as their enhanced permeability and retention effect and the tumor microenvironment. Multiple targeting molecules

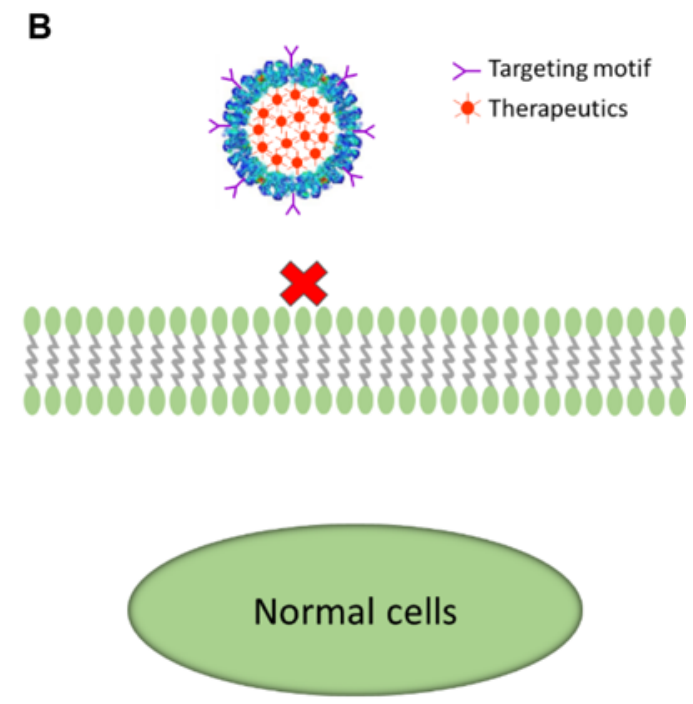

Fig. 3. Schematic diagram demonstrating the principle of viral nanoparticles as targeted anticancer vehicles for the treatment of cancer. (A) Viral nanoparticles encapsulated with anticancer therapeutics (or imaging agents) specifically target and bind cell membrane of cancer cells with overexpression of receptors. (B) Viral nanoparticles do not interfere with normal cells without overexpression of receptors. 
including tumor-homing peptides and targeting ligands or antibodies have been displayed on VNPs by chemical or genetic manners for anticancer drug delivery and tissue targeting [65]. The tumor-homing peptides involve AspGly-Arg (NGR), RGD and iRGD motif, human epidermal receptor (HER), 31-amino acid fragment of human high mobility group protein 2 (F3), epidermal growth factor receptor (EGFR), and VEGFR, while targeting ligands or antibodies include transferrin, folic acid (FA), and singlechain antibodies [66,67]. In addition to the artificial targeting, a subset of viruses, e.g. oncolytic viruses, present natural affinity for receptors which are usually up-regulated on tumor cells [68].

\subsection{Mammalian virus nanoparticles}

Mammalian viruses composed of viral envelope components or inactivated viral particles have been developed as delivery vehicles for therapeutic molecules by many researchers $[69,70]$. These virosomes demonstrate selective targeting and replication in tumor cells, meanwhile they have disadvantages such as immunogenicity and instability in the circulation. Among them, oncolytic viruses (OVs) are a group of viruses that selectively propagate and destroy cancer cells without causing excessive damage to normal tissues [71].

Adenovirus (Ad) is a non-enveloped dsDNA virus and has been the most extensively utilized OV model for human gene therapy [72]. Genetic manipulations of Ad NPs have been widely used for the improvement of performance and pathogenicity. For instance, Ad DNX-2401 (Delta-24-RGD) was constructed by a 24-bp deletion in early $1 \mathrm{~A}$ adenoviral gene $(E 1 A)$ which caused the virus incapable to replicate in normal cells while replication capable in tumor cells, and an RGD-motif was grafted in the fiber H-loop which led the virus to bind with $\alpha_{v} \beta_{3}$ or $\alpha_{v} \beta_{5}$ integrins and enhance targeting to tumor cells [73]. Further treatment with DNX2401 in phase I trial showed significant responses to longterm survival in recurrent malignant gliomas by prolonging survival in $20 \%$ of patients [74]. The hexon of adenovirus type 5 (Ad5) was shielded by humanized single-chain antibody variable fragment (scFv) to reduce off-targeting and immune neutralization in the liver, and the following equipment with adaptor proteins resulted with increased gene delivery to xenografted tumors expressing HER2 or EGFR [75]. In 2005, a genetically modified Ad5 named H101 (commercially sold as Oncorine ${ }^{\circledR}$ ) was first approved by Chinese regulators to treat neck and head cancer [76].

HSV is a neurotropic dsDNA virus and another widely used OV [78]. There are two known variants of HSV, among which HSV type 1 (HSV-1 or oHSV) has been studied in cancer therapy [77]. Todo et al. developed a triple-mutated HSV-1 named G47 by the deletion of $\gamma 34.5$ and $\alpha 47$ genes and the insertion of Escherichia coli LacZ gene inactivating the infected cell protein 6 gene (ICPO) [78]. The deletion of $\gamma 34.5$ resulted in cancer-selective replication and attenuation of pathogenicity, the deletion of $\alpha 47$ abrogated the down-regulation of major histocompatibility complex (MHC) class I expression and enhanced the antitumor immune responses, and the inactivation of ICP6 led to viral replication only in proliferating cells that express high enough levels of host ribonucleotide reductase. The replication of G47D was further augmented by small molecules of dilazep and dipyridamole, which improved virus growth and decreased tumor growth in athymic mice bearing subcutaneous Du145 tumors through inhibiting nucleoside transporter-1 [79]. HSV-1 shielded with murine interleukin-12 (IL-12) enhanced the antitumor activity against ovarian cancer, promoted the $\mathrm{CD} 8^{+} \mathrm{T}$-cell immune responses, and showed a significantly longer overall survival [80]. The genetically modified HSV-1 (OncoVex, $\mathrm{T} \mathrm{VEC}^{\circledR}$ ) expressing human granulocyte-macro-phage colony-stimulating factor (GM-CSF) was approved to treat advanced melanoma by the FDA and EMA in 2015 [81].

Paramyxovirus such as Newcastle disease virus (NDV) and measles virus (MV) have also been explored for cancer treatment [82,83]. Edmonston vaccine strains of MV exhibit significant antitumor activity against glioma stem cells in vitro and in vivo, and the recombinant MV-NIS encoding the human thyroidal sodium-iodide symporter (NIS) resulted in effective concentration of radioactive iodine in human tumor cells which can be used for gammacamera imaging of iodine-123 $\left({ }^{123} \mathrm{I}\right)$ uptake and radiovirotherapy by ${ }^{131} \mathrm{I}$ administration [84]. Phase I trial of patients with recurrent or refractory multiple myeloma using MVNIS showed relative safety and suggested to be a novel approach for the targeted infection and destruction of disseminated myeloma [85].

The truncated hepatitis B virus core antigen (tHBcAg) was engineered to construct $\mathrm{pH}$-responsive VNPs for controlled drug delivery [86]. The tHBcAg VNPs were loaded with DOX and polyacrylic acid (PAA), and then FA was conjugated to the external surface. The resulting FA$\mathrm{N}$-tHBcAg-PAA-DOX nanoparticles were $\mathrm{pH}$-responsive and released free DOX under simulated physiological conditions, leading to increased uptake of DOX in colorectal cancer cells and enhanced antitumour effects. The envelope protein of Moloney murine leukemia virus (Mo-MLV) was used to encapsulate fluorescent NPs and covalently linked with $\beta$-lactamase ( $\beta l a c$ ) [87]. The coated Mo-NPs mimicked native virus by binding mCAT- 1 receptor and $\beta$ lac activity was only detected in the cytosol of tumor cells indicating Mo-NPs could escape endosomes and then locate in the cytoplasm.

To date, only two genetically engineered OVs (Oncorine 
and T-VEC) have been approved as commercially available drugs. However, the major limitation of OVs and mammalian viruses is their immunogenicity and the humoral response, whether pre-existing or elicited by virus administration, which neutralizes their infectivity and limits the therapeutic effects [88].

\subsection{Plant virus nanoparticles}

Plant virus nanoparticles present an alternative approach for drug delivery vehicles. VNPs derived from plant viruses and bacteriophages are especially advantageous as they are less pathogenic and virulent in humans compared with mammalian viruses $[9,10]$. Plant viruses such as CPMV, CCMV, TMV, and potato virus X (PVX) demonstrate broad tissue distribution and rapid clearance with good blood and tissue biocompatibility $[89,90]$. Although there is no clinically approved nanomedicine based on plant viruses or bacteriophages, several preclinical trials are undergoing toward entering translational development.

CPMV has been explored as model plant virus for biomedical imaging and diseases targeting [91]. Apart from the aforementioned surface modification of CPMV by different ligand or peptides, the interior cavity of CPMV was also loaded with antineoplastic chemotherapeutics. CPMV was utilized to deliver mitoxantrone (MTO), a topoisomerase II inhibitor against primary brain tumor and glioblastoma multiforme (GBM), and the obtained MTOCPMV demonstrated enhanced cytotoxic effects against GBM cells in vitro [92]. HER2 epitope was attached with CPMV for epitope delivery and CPMV-HER2 inhibited the progression and metastasis of DDHER2 primary tumors in $\mathrm{Balb} / \mathrm{c}$ mice as well as prolonged the survival of mice [93].

CCMV has also been widely exploited for nanoscale fabrication and drug delivery [94]. A programmable chimeric CCMV was constructed for targeted drug delivery through the assembly of CCMV capsid protein conjugated with various molecules, i.e. CFSE/Alexa fluor as imaging agent, FA as targeting agent, and DOX as anticancer drug [95]. The chimeric system showed highly specific targeting to folate receptor and approximately $300 \%$ more cytotoxicity against Michigan cancer foundation-7 (MCF7) cells. Our group exploited the fusion expression of CCMV capsid protein with tumor-homing peptide F3, the resulting F3CCMV encapsulated near-infrared (NIR) fluorescent dye IR780 iodide for targeting delivery into MCF7 cells and induced photothermal effect in vitro [96].

TMV provides a fascinating platform for efficient drug delivery because of their structure transition between stacks of disks and rod-like spirals [97]. The platinum-based drug candidates phenanthriplatin (PhenPt) and cisplatin were integrated into the TMV cavity via either charge-driven reaction or covalent attachment $[98,99]$. PhenPt-TMV exhibited matched delivery efficacy in breast cancer MDAMB-231 xenografted mouse model compared with free PhenPt [98]. Cisplatin-loaded TMV showed efficient uptake by ovarian cancer cells and superior cytotoxicity and DNA double strand breakage in both platinum-sensitive and resistant cancer cells when compared to free cisplatin [99]. Another filamentous plant virus PVX was decorated with EGFR-targeting peptide ligand GE11 (YHWYGYTPQNVI), which presented successful targeting and partitioning toward $\mathrm{EGFR}^{+}$cancer cells and macrophages [100]. PVX was also employed to carry Herceptin (Trastuzumab) for targeted therapy in HER2 $2^{+}$breast cancer, inducing a much higher cell apoptosis in HER2 ${ }^{+}$cells compared with free Herceptin at similar concentration [101].

\subsection{Bacteriophages}

Bacteriophage MS2 possess diverse properties suitable for targeted drug delivery and cell imaging. MS2 capsids equipped with cell binding peptide SP94 (SFSIIHTPILPL) exhibited 104-fold higher affinity for human hepatocellular carcinoma (HCC) cells than other non-specific cells [102]. SP94-MS2 was further loaded with DOX, cisplatin, and 5fluorouracil showing selective killing of HCC cells, while SP94-MS2 encapsidated a siRNA cocktail prompted growth arrest and cell death of HCC cells. MS2 was also conjugated with iRGD peptide for targeted delivery of apoptosisinducing $\mathrm{Tl}^{+}$ions (Thallium), which caused apoptosis in human breast cancer cells MCF-7 and MDA-MB-231 as well as effected necrosis of these tumor xenografts in mice [103].

Bacteriophage $\mathrm{Q} \beta$ is highly stable and has been used for ligands and proteins displaying on the exterior surface. Rhee et al. utilized Q $\beta$ VLPs to encapsulate multiple copies of fluorescent proteins by specific engineered RNA-protein interactions [104]. The resulting VLPs were attached with 9-biphenylcarbonyl (BPC)-sialoside moieties via CuAAC reaction, which showed selective entry into Chinese hamster ovary cells through the recognition between BPCsialoside and CD22 receptor. PEGylation was employed to modify the surface of Q $\beta$ VLPs by the attachment of PEG via thiol-dibromomaleimide chemistry [23]. PEGylated Q $\beta$ VLPs were further installed with approximately 530 photocleavable DOX complexes for photocaging therapy by CuAAC reaction. The dual-functionalized VLPs showed negligible cytotoxicity before photoactivation, whereas highly controllable photo-release and cell killing power were also confirmed.

\subsection{Other protein cage nanoparticles}

In nature, heat shock protein (Hsp), ferritin, apoferritin (Apf), and other small proteins can also self-assemble into protein cage architecture like viral capsids [105]. These 
spherical NPs can serve as drug delivery vehicles just like virus and VNPs.

Hsp derived from Methanococcus jannaschii was modified with cell-specific targeting moieties by both genetic and chemical strategies [106]. A tumor vasculature targeting peptide RGD-4C (CDCRGDCFC) and anti-CD4 antibodies were both incorporated onto the exterior of Hsp cage, which exhibited specific bounding to $\mathrm{CD} 4^{+}$cells. Genetically modified Hsp cage was also loaded with DOX, showing selective releasement in a $\mathrm{pH}$ dependent manner [107].

Ferritin is an iron storage protein presented in all living systems, which self-assembles into a 24-mer capsid with a diameter of $12 \mathrm{~nm}$ [108]. Kanekiyo et al. exploited the ferritin-NP system to display Epstein-Barr virus (EBV) major envelope glycoprotein 350/220 (gp350), resulting in 10- to 100-fold increased neutralization compared with soluble gp350 in a mouse model [109]. As the iron-free form of ferritin, Apf can load molecular cargoes such as high dose of DOX and docetaxel (DOC), specifically bound and deliver them into MCF7 and HeLa cell lines, and enhance $\mathrm{G} 2 / \mathrm{M}$ phase arrest and apoptosis compared to free drugs [110].

Bovine serum albumin (BSA) can comprise biocompatible nanoparticles and be constructed as nanocarriers for organic selenocompound (PSeD) decorated with FA as the targeting ligand [111]. The cancer-targeted nanosystem drastically increased reactive oxygen species overproduction, VEGF/VEGFR2 inactivation, and inhibition of XRCC-1mediated repair of DNA damage in Hela cells. Encapsulin, isolated from thermophilic bacteria Thermotoga maritima, was genetically engineered with unusual heat stability and SP94 peptide [112]. Aldoxorubicin (AlDox) was chemically packaged inside SP94-Encapsulin via thiol-maleimide Michael-type addition for targeted delivery to HepG2 cells, displaying comparable killing efficacy with free AlDox. The thermostable E2 subunit of pyruvate dehydrogenase was utilized to construct approximately $27-\mathrm{nm}$ dodecahedral protein NPs [113]. The internal cavity was loaded with Alexa Fluor 532 (AF532) and DOX, the external surface was shielded with PEG or FA, and the bi-functional NPs showed cell uptake six times greater than non-targeting NPs.

\section{Applications of Viral Nanoparticles}

\subsection{Contrast agents for biological imaging}

A contrast agent is a substance which can increase the imaging intensity of cellular components. A variety of contrast agents have been developed for optical imaging, ultrasound imaging, computed tomography (CT), magnetic resonance imaging (MRI), and positron emission tomography (PET) $[114,115]$. In order to reveal biological processes with disease present in the living subjects, an ideal imaging contrast agent should have high intensity at the desired site with minimal toxicity [116]. Intensive research efforts have been made aiming to achieve a satisfactory signal-to-noise ratio. In this regard, VNPs provides more advantages over synthetic nanoparticles such as short circulation and retention time, possible evasion by the immune system, and negligible side effects [117]. Furthermore, VNPs can be engineered with diverse fluorescent labels and/or contrast agents along with targeting aptamers, peptides, or antibodies for specific binding with targeted cells and tissues [12].

The interior and exterior surfaces of MS2 were conjugated with gadolinium chelates $\left(\mathrm{Gd}^{3+}\right)$ to fabricate MRI contrast agents [118]. The proton nuclear magnetic relaxation dispersion profiles of the conjugates showed up to a 5-fold increase in relaxivity, with reduced systemic toxicity compared with free $\mathrm{Gd}^{3+}$ ion. Multifunctional PVX was constructed by loading Gd-dodecane tetraacetic acid to lysines for MRI and installing fluorescent dye O488 to cysteines for optical imaging [119]. The resulting nanofilament displayed significantly enhanced relaxivities as well as good fluorescent properties by showing no quenching, which could be used in dual-modal opticalMRI imaging applications. The internal cavity of TMV was loaded with a dysprosium $\left(\mathrm{Dy}^{3+}\right)$ complex and NIR fluorescent dye Cy7.5, and the external surface was conjugated with an Asp-Gly-Glu-Ala (DGEA) peptide to target integrin $\alpha_{2} \beta_{1}$ [120]. The resulting Dy-Cy7.5-TMVDGEA NPs demonstrated a high transverse relaxivity for MRI and target specificity with PC-3 prostate cancer cells and tumors in vitro and in vivo.

The inside surface of MS2 have also been addressed with $\left[{ }^{18} \mathrm{~F}\right]$-fluorobenzaldehyde and evaluated in rats for PET imaging, which showed a much longer circulation time of over $3 \mathrm{~h}$ for $\left[{ }^{18} \mathrm{~F}\right]-\mathrm{MS} 2 \mathrm{NPs}$ compared with $0.5 \mathrm{~h}$ of free $\left[{ }^{18} \mathrm{~F}\right]-$ fluorobenzaldehyde [121]. CPMV was fluorescently labeled with high densities of Alexa Fluor 555 (A555) without any measurable quenching, and the resulting exceptionally bright VNPs were assessed for intravital vascular imaging [122]. CPMV-A555 exhibited high-resolution intravital imaging of vascular endothelium for periods of at least $72 \mathrm{~h}$ and a depth of up to $500 \mu \mathrm{m}$ in the vasculature and blood flow of living mouse and chick embryos. Moreover, the intravital visualization of human fibrosarcoma-mediated tumor angiogenesis using CPMVA555 offers a measure to evaluate arterial and venous vessels and to examine the neovascularization of the tumor microenvironment. 


\subsection{Gene therapy}

Gene therapy is a prospective approach to treat myriad genetic and acquired diseases [123]. As the natural vehicles for delivery of genes, virus has the most advantage for therapeutic nucleic acids delivery. Currently about twothirds of gene therapy in clinical trials are using viruses as transportation vectors, among which mammalian viruses are majority [124].

Ad and AAV vectors have been developed as delivery vehicles for CRISPR components by many research groups. Maggio and co-workers used early region $1(E 1)$ and early region 2A $(E 2 A)$-deleted Ad vector for the delivery of Cas9-protein/gRNA complexes into transformed and nontransformed cells, resulting targeted mutagenesis ranging from $18 \%$ to $65 \%$ across different human cell types [125]. Li et al. constructed a AAV8 mediated delivery of CRISPRSaCas9 system compatible with hepatitis B virus (HBV) core region derived guide-RNA for the inhibition of chronic HBV infection, which showed declined levels of serum HBsAg, HBeAg, and HBV DNA in HBV transgenic mice during 58 days observation [126]. Yin et al. utilized lipid NPs for the delivery of Cas9 mRNA with AAV encoding a sgRNA and a repair template to repair human hereditary tyrosinemia in mouse model, showing fumarylacetoacetate hydrolase (Fah)-positive hepatocytes generated with the efficiency of $>6 \%$ of hepatocytes after a single Fahsplicing mutation [127].

Due to their capability to persist in humans after primary infection, HSV has been used as vehicles to delivery genes to cells in vivo [128]. HSV vectors have been successfully applied in animal models for the treatment against cancer, among which HSV-1 is the most extensively studied [129]. Lin et al. engineered CRISPR/Cas9-mediated editing of the HSV-1 genome, which demonstrated that two copies of $I C P 0$ in different locations could be simultaneously edited with high efficiency and without off-target editions [130]. Roehm et al. utilized lentiviral-mediated transfection of CRISPR/Cas9 to target $I C P 0$ combined with ICP4 or ICP27 in HSV-1 genome, causing complete inhibition of HSV-1 infection [131].

\subsection{Drug delivery}

Nanoparticles-based drug delivery can provide targeted and intracellular delivery, promote enhanced drug-therapeutic efficiency, and minimize required doses by reducing immunogenicity and increasing the solubility and specificity $[132,133]$. As the aforementioned examples, VNPs can also improve the bioavailability, enable controlled release upon physiological conditions, and deliver two or more therapeutic compounds for combination therapy.

To enhance the delivery and targeting efficiency of VNPs, several approaches were employed such as PEGylation and coating. PEGylation is a common strategy to reduce or eliminate biospecific interactions by the attachment of PEG [134]. PEGylated versions of VNPs have been constructed with CPMV, PVX, TMV, and MS2, which shielded their interactions with cells and prevented VNPs from triggering a primary immune response [135-137]. Although shielding efficiency is dependent on the PEG chain length, only minimal surface coverage $(<1 \%)$ is needed to block CPMVcell interactions [135]. Similar data were also reported for PEGylated PVX and TMV formulations [136,137]. The coating of DNA origami nanostructures with CCMV capsid proteins through electrostatic interactions augmented cellular delivery to human HEK293 cells, which proved 13-fold higher for cellular attachment and delivery of origamis compared to bare DNA origamis [138].

\subsection{Subunit vaccines}

As the world is currently going through an epidemic of a novel coronavirus (2019-nCoV), we should think prudently how to deal with viruses and use them as a potentially vast and beneficial resource [139]. A most recent example was the repurposing of nonstructural protein 10 (NSP10) from the replicase polyprotein 1a of human severe acute respiratory syndrome (SARS) coronavirus to exploit a selfassembling platform for antigen presentation and vaccine development, e.g. the truncated Herpesvirus saimiri gD protein fusion-expressed with NSP10 as a therapeutic vaccine for idiopathic pulmonary fibrosis [140]. Viruses have been proven as useful development platform for novel vaccines because of their particulate and repetitive nature.

There are several viral vaccines against cancer commercially available now, including HBV and human papillomavirus (HPV) vaccines [141]. Zhai et al. developed an HPV vaccine candidate composed of MS2 VLPs displaying the mixture of different peptides of HPV capsid protein L2 [142]. The mixed MS2-L2 VLPs protected mice against eleven oncogenic HPV types associated with approximately $95 \%$ of cervical cancer. Speiser et al. constructed a therapeutic human VLP-based vaccine Q $\beta($ G10)-Melan-A through installing the melanoma differentiation specific antigen Melan-A/Mart1 to Q $\beta$ VLPs packaged with the targeting TLR-9 ligand G10 (a type-A CpG) for DCs and $\mathrm{CD}^{+} \mathrm{T}$ cells [143]. Phase I/II study of $\mathrm{Q} \beta(\mathrm{G} 10)-$ Melan-A in Stage II/IV melanoma patients showed promising results with $63 \%$ of the patients generating specific $\mathrm{T}$ cell responses to produce high cytokine levels (IFN- $\gamma$, TNF- $\alpha$, and IL-2). Shukla et al. utilized CPMV for HER2 epitope delivery, revealing efficient lymphatic drainage, high uptake and activation with antigen presenting cells, and enhanced antiHER2 immunity [93]. The CPMV-HER2 vaccine candidate postponed the progression and metastasis of DDHER2 primary tumors in Balb/c mice. Cai et al. compared three 
icosahedral plant VNPs of CPMV, CCMV, and sesbania mosaic virus (SeMV) for their capability of displaying HER2 epitope [144]. Although these obtained VNPs showed similar shape and structure, the immune profiles elicited by them were significantly different, whereas a Th1 predominant immune response was observed for CPMV-HER2 while a Th2 type for CCMV- and SeMV-HER2. The results demonstrated that the VNP carrier itself can play a key role in the regulation of Th1/Th2 differentiation.

\section{Summary and Future Outlook}

The application of VNPs in drug delivery has taken tremendous steps forward in last 20 years. In the field of drug delivery, contrast agents, gene therapy, and viral vaccines, numerous VNPs-based platforms are now under various stages of preclinical and clinical development [145]. The currently approved VNP systems have highlighted the therapeutic potential of anticancer drugs by improving drug efficacy or reducing drug toxicity, even overcoming the disadvantages of immunogenicity or biocompatibility [146].

However, there are still some concerns for pushing viral drug delivery research forward. The first and biggest obstacle is whether pre-existing or elicited immunity would be initiated with the virus administration that generally lead to adverse effects or limit therapeutic effects [147]. The second bottleneck is the large-scale manufacturing process and techniques associated with formulation quality control and assurance of viral products [148]. The last hurdle is the safety issue of VNPs should be thoroughly tested and examined for long period before clinical application [149]. With the introduction of safer nanomaterials and novel engineering approaches, the field of viral drug delivery will continue to grow and flourish, and more multifunctional nanoparticles may be expected to enter into clinical practice in the near future.

\section{Acknowledgements}

This study was funded by Shandong Provincial Key Research and Development Program (International Science and Technology Cooperation, Grant No. 2019GHZ033), International Science and Technology Cooperation Program of Shandong Academy of Sciences (Grant No. 2019GHPY05).

\section{Ethical Statements}

The authors declare no conflict of interest.
Neither ethical approval nor informed consent was required for this study.

\section{Nomenclature}

AAV : adeno-associated virus

Ad : adenovirus

AlDox : aldoxorubicin

ASGPRs : asialoglycoprotein receptors

Apf : apoferritin

biRNA : bifunctional linker RNA

Blac : $\beta$-lactamase

BPC : 9-biphenylcarbonyl

BSA : bovine serum albumin

CCMV : cowpea chlorotic mottle virus

CPMV : cowpea mosaic virus

CT : computed tomography

CuAAC : copper(I)-catalyzed azide-alkyne cycloaddition

DOC : docetaxel

DOX : doxorubicin

E1A : early $1 \mathrm{~A}$ adenoviral

EGFP : enhanced green fluorescent protein

EGFR : epidermal growth factor receptor

FA : folic acid

Fah : fumarylacetoacetate hydrolase

GBM : glioblastoma multiforme

GM-CSF : granulocyte-macro-phage colony-stimulating factor

HBV : hepatitis B virus

HCC : human hepatocellular carcinoma

HepG2 : human hepatocellular carcinomas

HER : human epidermal receptor

HPV : human papillomavirus

Hsps : heat shock proteins

HSV : herpes simplex virus

ICP6 : infected cell protein 6

MCF7 : Michigan cancer foundation-7

MHC : major histocompatibility complex

Mo-MLV : Moloney murine leukemia virus

MRI : magnetic resonance imaging

MTO : mitoxantrone

MV : measles virus

NDV : Newcastle disease virus

NHS : N-hydroxysuccinimide

NIR : near-infrared

NIS : sodium-iodide symporter

NPs : nanoparticles

NSP10 : nonstructural protein 10

OVs : oncolytic viruses

PAA : polyacrylamide

PEG : polyethylene glycol 


$\begin{array}{ll}\text { PET } & : \text { positron emission tomography } \\ \text { PhenPt } & : \text { phenanthriplatin } \\ \text { PSeD } & : \text { selenocompound } \\ \text { PVX } & : \text { potato virus X } \\ \text { RCNMV } & \text { : red clover necrotic mosaic virus } \\ \text { SARS } & : \text { severe acute respiratory syndrome } \\ \text { ScFv } & : \text { single-chain antibody variable fragment } \\ \text { SeMV } & : \text { sesbania mosaic virus } \\ \text { SiRNA } & : \text { small interfering RNA } \\ \text { tHBcAg } & : \text { truncated hepatitis B virus core antigen } \\ \text { TMV } & : \text { tobacco mosaic virus } \\ \text { VEGFR } & : \text { vascular endothelial growth factor receptor } \\ \text { VLPs } & : \text { virus-like particles } \\ \text { VNPs } & : \text { viral nanoparticles }\end{array}$

\section{References}

1. Drbohlavova, J., J. Chomoucka, V. Adam, M. Ryvolova, T. Eckschlager, J. Hubalek, and R. Kizek (2013) Nanocarriers for anticancer drugs - new trends in nanomedicine. Curr. Drug Metab. 14: 547-564.

2. Sercombe, L., T. Veerati, F. Moheimani, S. Y. Wu, A. K. Sood, and S. Hua (2015) Advances and challenges of liposome assisted drug delivery. Front. Pharmacol. 6: 286.

3. Kamaly, N., Z. Xiao, P. M. Valencia, A. F. Radovic-Moreno, and O. C. Farokhzad (2012) Targeted polymeric therapeutic nanoparticles: design, development and clinical translation. Chem. Soc. Rev. 41: 2971-3010.

4. Wang, F., C. Li, J. Cheng, and Z. Yuan (2016) Recent advances on inorganic nanoparticle-based cancer therapeutic agents. Int. J. Environ. Res. Public Health. 13: 1182.

5. Chung, Y. H., H. Cai, and N. F. Steinmetz (2020) Viral nanoparticles for drug delivery, imaging, immunotherapy, and theranostic applications. Adv. Drug Deliv. Rev. 156: 214-235.

6. Sanvicens, N. and M. P. Marco (2008) Multifunctional nanoparticles-properties and prospects for their use in human medicine. Trends Biotechnol. 26: 425-433.

7. Srinivasan, M., M. Rajabi, and S. A. Mousa (2015) Multifunctional nanomaterials and their applications in drug delivery and cancer therapy. Nanomaterials. 5: 1690-1703.

8. Sykes, E. A., Q. Dai, C. D. Sarsons, J. Chen, J. V. Rocheleau, D. M. Hwang, G. Zheng, D. T. Cramb, K. D. Rinker, and W. C. Chan (2016) Tailoring nanoparticle designs to target cancer based on tumor pathophysiology. Proc. Natl. Acad. Sci. U.S.A. 113: E1142-E1151.

9. Steinmetz, N. F. (2010) Viral nanoparticles as platforms for next-generation therapeutics and imaging devices. Nanomedicine. 6: 634-641.

10. Ma, Y., R. J. M. Nolte, and J. J. L. M. Cornelissen (2012) Virusbased nanocarriers for drug delivery. Adv. Drug Deliv. Rev. 64: 811-825.

11. Xin, Y., M. Yin, L. Zhao, F. Meng, and L. Luo (2017) Recent progress on nanoparticle-based drug delivery systems for cancer therapy. Cancer Biol. Med. 14: 228-241.

12. Rohovie, M. J., M. Nagasawa, and J. R. Swartz (2017) Virus-like particles: Next-generation nanoparticles for targeted therapeutic delivery. Bioeng. Transl. Med. 2: 43-57.

13. Zdanowicz, M. and J. Chroboczek (2016) Virus-like particles as drug delivery vectors. Acta Biochim. Pol. 63: 469-473.

14. Cho, K., X. Wang, S. Nie, Z. G. Chen, and D. M. Shin (2008)
Therapeutic nanoparticles for drug delivery in cancer. Clin. Cancer Res. 14: 1310-1316.

15. Manchester, M. and P. Singh (2006) Virus-based nanoparticles (VNPs): platform technologies for diagnostic imaging. $A d v$. Drug Deliv. Rev. 58: 1505-1522.

16. Yildiz, I., S. Shukla, and N. F. Steinmetz (2011) Applications of viral nanoparticles in medicine. Curr. Opin. Biotechnol. 22: 901-908.

17. Pokorski, J. K. and N. F. Steinmetz (2011) The art of engineering viral nanoparticles. Mol. Pharm. 8: 29-43.

18. Li, F. and Q. Wang (2014) Fabrication of nanoarchitectures templated by virus-based nanoparticles: strategies and applications. Small. 10: 230-245.

19. Sherman, M. B., R. H. Guenther, F. Tama, T. L. Sit, C. L. Brooks, A. M. Mikhailov, E. V. Orlova, T. S. Baker, and S. A. Lommel (2006) Removal of divalent cations induces structural transitions in red clover necrotic mosaic virus, revealing a potential mechanism for RNA release. J. Virol. 80: 1039510406.

20. Kwak, M., I. J. Minten, D. M. Anaya, A. J. Musser, M. Brasch, R. J. M. Nolte, K. Müllen, J. J. L. M. Cornelissen, and A. Herrmann (2010) Virus-like particles templated by DNA micelles: a general method for loading virus nanocarriers. $J$. Am. Chem. Soc. 132: 7834-7835.

21. Dixit, S. K., N. L. Goicochea, M. C. Daniel, A. Murali, L. Bronstein, M. De, B. Stein, V. M. Rotello, C. C. Kao, and B. Dragnea (2006) Quantum dot encapsulation in viral capsids. Nano Lett. 6: 1993-1999.

22. Raja, K. S., Q. Wang, M. J. Gonzalez, M. Manchester, J. E. Johnson, and M. G. Finn (2003) Hybrid virus-polymer materials. 1. Synthesis and properties of PEG-decorated cowpea mosaic virus. Biomacromolecules. 4: 472-476.

23. Chen, Z., N. Li, L. Chen, J. Lee, and J. J. Gassensmith (2016) Dual functionalized bacteriophage $\mathrm{Q} \beta$ as a photocaged drug carrier. Small. 12: 4563-4571.

24. Lu, Y. and C. O. Madu (2010) Viral-based gene delivery and regulated gene expression for targeted cancer therapy. Expert Opin. Drug Deliv. 7: 19-35.

25. Jin, S. and K. Ye (2007) Nanoparticle-mediated drug delivery and gene therapy. Biotechnol. Prog. 23: 32-41.

26. Liu, T. C. and D. Kirn (2008) Gene therapy progress and prospects cancer: oncolytic viruses. Gene Ther. 15: 877-884.

27. Elzoghby, A. O., W. M. Samy, and N. A. Elgindy (2012) Protein-based nanocarriers as promising drug and gene delivery systems. J. Control. Release. 161: 38-49.

28. Ng, B. C. H. (2010) Encapsulation of synthetic materials in biological self-assembled systems. Ph.D. Thesis. University of California, LA, USA.

29. Shen, L., N. Bao, Z. Zhou, P. E. Prevelige, and A. Gupta (2011) Materials design using genetically engineered proteins. J. Mater. Chem. 21: 18868-18876.

30. Liu, Z., J. Qiao, Z. Niu, and Q. Wang (2012) Natural supramolecular building blocks: from virus coat proteins to viral nanoparticles. Chem. Soc. Rev. 41: 6178-6194.

31. Zlotnick, A. and S. J. Stray (2003) How does your virus grow? Understanding and interfering with virus assembly. Trends Biotechnol. 21: 536-542.

32. Bancroft, J. B., E. Hiebert, and C. E. Bracker (1969) The effects of various polyanions on shell formation of some spherical viruses. Virology. 39: 924-930.

33. $\mathrm{Hu}, \mathrm{Y} ., \mathrm{R}$. Zandi, A. Anavitarte, C. M. Knobler, and W. M. Gelbart (2008) Packaging of a polymer by a viral capsid: the interplay between polymer length and capsid size. Biophys. $J$. 94: 1428-1436.

34. Douglas, T. and M. Young (1998) Host-guest encapsulation of materials by assembled virus protein cages. Nature. 393: 152-155. 
35. Comellas-Aragonès, M., H. Engelkamp, V. I. Claessen, N. A. J. M. Sommerdijk, A. E. Rowan, P. C. M. Christianen, J. C. Maan, B. J. M. Verduin, J. J. L. M. Cornelissen, and R. J. Nolte (2007) A virus-based single-enzyme nanoreactor. Nat. Nanotechnol. 2: 635-639.

36. Wu, Y., H. Yang, and H. J. Shin (2014) Encapsulation and crystallization of Prussian blue nanoparticles by cowpea chlorotic mottle virus capsids. Biotechnol. Lett. 36: 515-521.

37. Speir, J. A., S. Munshi, G. Wang, T. S. Baker, and J. E. Johnson (1995) Structures of the native and swollen forms of cowpea chlorotic mottle virus determined by X-ray crystallography and cryo-electron microscopy. Structure. 3: 63-78.

38. Douglas, T., E. Strable, D. Willits, A. Aitouchen, M. Libera, and M. Young (2002) Protein engineering of a viral cage for constrained nanomaterials synthesis. Adv. Mater. 14: 415-418.

39. Brasch, M., A. de la Escosura, Y. Ma, C. Uetrecht, A. J. R. Heck, T. Torres, and J. J. L. M. Cornelissen (2011) Encapsulation of phthalocyanine supramolecular stacks into virus-like particles. J. Am. Chem. Soc. 133: 6878-6881.

40. Zhang, Y., Y. Dong, J. Zhou, X. Li, and F. Wang (2018) Application of plant viruses as a biotemplate for nanomaterial fabrication. Molecules. 23: 2311.

41. Tama, F. and C. L. Brooks 3rd (2002) The mechanism and pathway of $\mathrm{pH}$ induced swelling in cowpea chlorotic mottle virus. J. Mol. Biol. 318: 733-747.

42. Lockney, D. M., R. N. Guenther, L. Loo, W. Overton, R. Antonelli, J. Clark, M. Hu, C. Luft, S. A. Lommel, and S. Franzen (2011) The red clover necrotic mosaic virus capsid as a multifunctional cell targeting plant viral nanoparticle. Bioconjug. Chem. 22: 67-73.

43. Huang, Y., C. Y. Chiang, S. K. Lee, Y. Gao, E. L. Hu, J. De Yoreo, and A. M. Belcher (2005) Programmable assembly of nanoarchitectures using genetically engineered viruses. Nano Lett. 5: 1429-1434.

44. Aniagyei, S. E., C. DuFort, C. C. Kao, and B. Dragnea (2008) Self-assembly approaches to nanomaterial encapsulation in viral protein cages. J. Mater. Chem. 18: 3763-3774.

45. Zhao, Q., W. Chen, Y. Chen, L. Zhang, J. Zhang, and Z. Zhang (2011) Self-assembled virus-like particles from rotavirus structural protein VP6 for targeted drug delivery. Bioconjug. Chem. 22: 346-352.

46. Fiedler, J. D., M. R. Fishman, S. D. Brown, J. Lau, and M. G. Finn (2018) Multifunctional enzyme packaging and catalysis in the Qß protein nanoparticle. Biomacromolecules. 19: 3945-3957.

47. Wu, Y., H. Yang, and H. J. Shin (2013) Viruses as self-assembled nanocontainers for encapsulation of functional cargoes. Korean J. Chem. Eng. 30: 1359-1367.

48. Balke, I. and A. Zeltins (2019) Use of plant viruses and viruslike particles for the creation of novel vaccines. Adv. Drug Deliv. Rev. 145: 119-129.

49. Minten, I. J., L. J. A. Hendriks, R. J. M. Nolte, and J. J. L. M. Cornelissen (2009) Controlled encapsulation of multiple proteins in virus capsids. J. Am. Chem. Soc. 131: 17771-17773.

50. Sharma, J., M. Uchida, H. M. Miettinen, and T. Douglas (2017) Modular interior loading and exterior decoration of a virus-like particle. Nanoscale. 9: 10420-10430.

51. Francis, M. B. and I. S. Carrico (2010) New frontiers in protein bioconjugation. Curr. Opin. Chem. Biol. 14: 771-773.

52. Lee, L. A., Z. Niu, and Q. Wang (2009) Viruses and virus-like protein assemblies-chemically programmable nanoscale building blocks. Nano Res. 2: 349-364.

53. Smith, M. T., A. K. Hawes, and B. C. Bundy (2013) Reengineering viruses and virus-like particles through chemical functionalization strategies. Curr. Opin. Biotechnol. 24: 620-626.

54. Abello, N., H. A. M. Kerstjens, D. S. Postma, and R. Bischoff (2007) Selective acylation of primary amines in peptides and proteins. J. Proteome Res. 6: 4770-4776.

55. Wang, Q., E. Kaltgrad, T. Lin, J. E. Johnson, and M. G. Finn (2002) Natural supramolecular building blocks: Wild-type cowpea mosaic virus. Chem. Biol. 9: 805-811.

56. Strable, E. and M. G. Finn (2009) Chemical modification of viruses and virus-like particles. Curr. Top Microbiol. Immunol. 327: $1-21$.

57. Rostovtsev, V. V., L. G. Green, V. V. Fokin, and K. B. Sharpless (2002) A stepwise huisgen cycloaddition process: copper(I)catalyzed regioselective "ligation" of azides and terminal alkynes. Angew. Chem. Int. Ed. Engl. 41: 2596-2599.

58. Gupta, S. S., J. Kuzelka, P. Singh, W. G. Lewis, M. Manchester, and M. G. Finn (2005) Accelerated bioorthogonal conjugation: A practical method for the ligation of diverse functional molecules to a polyvalent virus scaffold. Bioconjug. Chem. 16: 1572-1579.

59. Hong, V., S. I. Presolski, C. Ma, and M. G. Finn (2009) Analysis and optimization of copper-catalyzed azide-alkyne cycloaddition for bioconjugation. Angew. Chem. Int. Ed. Engl. 48: 9879-9883.

60. Wang, Q., T. R. Chan, R. Hilgraf, V. V. Fokin, K. B. Sharpless, and M. G. Finn (2003) Bioconjugation by copper(I)-catalyzed azide-alkyne $[3+2]$ cycloaddition. J. Am. Chem. Soc. 125: 3192-3193.

61. Destito, G., R. Yeh, C. S. Rae, M. G. Finn, and M. Manchester (2007) Folic acid-mediated targeting of cowpea mosaic virus particles to tumor cells. Chem. Biol. 14: 1152-1162.

62. Wu, Y., H. Yang, Y. J. Jeon, M. Y. Lee, J. Li, and H. J. Shin (2014) Surface modification of cowpea chlorotic mottle virus capsids via a copper(I)-catalyzed azide-alkyne cycloaddition (CuAAC) reaction and their adhesion behavior with HeLa cells. Biotechnol. Bioprocess Eng. 19: 747-753.

63. Dirksen, A. and P. E. Dawson (2008) Rapid oxime and hydrazone ligations with aromatic aldehydes for biomolecular labeling. Bioconjug. Chem. 19: 2543-2548.

64. Brunel, F. M., J. D. Lewis, G. Destito, N. F. Steinmetz, M. Manchester, H. Stuhlmann, and P. E. Dawson (2010) Hydrazone ligation strategy to assemble multifunctional viral nanoparticles for cell imaging and tumor targeting. Nano Lett. 10: 1093-1097.

65. Mateu, M. G. (2011) Virus engineering: functionalization and stabilization. Protein Eng. Des. Sel. 24: 53-63.

66. Ruoslahti, E. (2012) Peptides as targeting elements and tissue penetration devices for nanoparticles. Adv. Mater. 24: 3747-3756.

67. Wen, A. M., P. H. Rambhia, R. H. French, and N. F. Steinmetz (2013) Design rules for nanomedical engineering: from physical virology to the applications of virus-based materials in medicine. J. Biol. Phys. 39: 301-325.

68. Mohanty, C., M. Das, J. R. Kanwar, and S. K. Sahoo (2011) Receptor mediated tumor targeting: an emerging approach for cancer therapy. Curr. Drug Deliv. 8: 45-58.

69. Lund, P. E., R. C. Hunt, M. M. Gottesman, and C. KimchiSarfaty (2010) Pseudovirions as vehicles for the delivery of siRNA. Pharm. Res. 27: 400-420.

70. Giacca, M. and S. Zacchigna (2012) Virus-mediated gene delivery for human gene therapy. J. Control. Release. 161: 377-388.

71. Chiocca, E. A. and S. D. Rabkin (2014) Oncolytic viruses and their application to cancer immunotherapy. Cancer Immunol. Res. 2: 295-300.

72. Breyer, B., W. Jiang, H. Cheng, L. Zhou, R. Paul, T. Feng, and T. C. He (2001) Adenoviral vector-mediated gene transfer for human gene therapy. Curr. Gene Ther. 1: 149-162.

73. Fueyo, J., R. Alemany, C. Gomez-Manzano, G. N. Fuller, A. Khan, C. A. Conrad, T. J. Liu, H. Jiang, M. G. Lemoine, K. Suzuki, R. Sawaya, D. T. Curiel, W. K. A. Yung, and F. F. Lang (2003) Preclinical characterization of the antiglioma activity of a tropism-enhanced adenovirus targeted to the retinoblastoma pathway. J. Natl. Cancer Inst. 95: 652-660. 
74. Lang, F. F., C. Conrad, C. Gomez-Manzano, W. K. A. Yung, R. Sawaya, J. S. Weinberg, S. S. Prabhu, G. Rao, G. N. Fuller, K. D. Aldape, J. Gumin, L. M. Vence, I. Wistuba, J. RodriguezCanales, P. A. Villalobos, C. M. F. Dirven, S. Tejada, R. D. Valle, M. M. Alonso, B. Ewald, J. J. Peterkin, F. Tufaro, and J. Fueyo (2018) Phase I study of DNX-2401 (Delta-24-RGD) oncolytic adenovirus: replication and immunotherapeutic effects in recurrent malignant glioma. J. Clin. Oncol. 36: 1419-1427.

75. Schmid, M., P. Ernst, A. Honegger, M. Suomalainen, M. Zimmermann, L. Braun, S. Stauffer, C. Thom, B. Dreier, M. Eibauer, A. Kipar, V. Vogel, U. F. Greber, O. Medalia, and A. Plückthun (2018) Adenoviral vector with shield and adapter increases tumor specificity and escapes liver and immune control. Nat. Commun. 9: 450.

76. Ma, G., H. Shimada, K. Hiroshima, Y. Tada, N. Suzuki, and M. Tagawa (2009) Gene medicine for cancer treatment: commercially available medicine and accumulated clinical data in China. Drug Des. Devel. Ther. 2: 115-122.

77. Sanchala, D. S., L. K. Bhatt, and K. S. Prabhavalkar (2017) Oncolytic herpes simplex viral therapy: a stride toward selective targeting of cancer cells. Front. Pharmacol. 8: 270.

78. Todo, T., R. L. Martuza, S. D. Rabkin, and P. A. Johnson (2001) Oncolytic herpes simplex virus vector with enhanced MHC class I presentation and tumor cell killing. Proc. Natl. Acad. Sci. US A. 98: 6396-6401.

79. Passer, B. J., T. Cheema, B. Zhou, H. Wakimoto, C. Zaupa, M. Razmjoo, J. Sarte, S. Wu, C. Wu, J. W. Noah, Q. Li, J. K. Buolamwini, Y. Yen, S. D. Rabkin, and R. L. Martuza (2010) Identification of the ENT1 antagonists dipyridamole and dilazep as amplifiers of oncolytic herpes simplex virus-1 replication. Cancer Res. 70: 3890-3895.

80. Thomas, E. D., S. Meza-Perez, K. S. Bevis, T. D. Randall, G. Y. Gillespie, C. Langford, and R. D. Alvarez (2016) IL-12 Expressing oncolytic herpes simplex virus promotes anti-tumor activity and immunologic control of metastatic ovarian cancer in mice. J. Ovarian Res. 9: 70.

81. Pol, J., G. Kroemer, and L. Galluzzi (2016) First oncolytic virus approved for melanoma immunotherapy. Oncoimmunology. 5: e1115641.

82. Kelly, E. and S. J. Russell (2007) History of oncolytic viruses: genesis to genetic engineering. Mol. Ther. 15: 651-659.

83. Haralambieva, I., I. Iankov, K. Hasegawa, M. Harvey, S. J. Russell, and K. W. Peng (2007) Engineering oncolytic measles virus to circumvent the intracellular innate immune response. Mol. Ther. 15: 588-597.

84. Allen, C., M. Opyrchal, I. Aderca, M. A. Schroeder, J. N. Sarkaria, E. Domingo, M. J. Federspiel, and E. Galanis (2013) Oncolytic measles virus strains have significant antitumor activity against glioma stem cells. Gene Ther. 20: 444-449.

85. Dispenzieri, A., C. Tong, B. LaPlant, M. Q. Lacy, K. Laumann, D. Dingli, Y. Zhou, M. J. Federspiel, M. A. Gertz, S. Hayman, F. Buadi, M. O'Connor, V. J. Lowe, K. W. Peng, and S. J. Russell (2017) Phase I trial of systemic administration of Edmonston strain of measles virus genetically engineered to express the sodium iodide symporter in patients with recurrent or refractory multiple myeloma. Leukemia. 31: 2791-2798.

86. Biabanikhankahdani, R., N. B. M. Alitheen, K. L. Ho, and W. S. Tan (2016) pH-responsive virus-like nanoparticles with enhanced tumour-targeting ligands for cancer drug delivery. Sci. Rep. 6: 37891 .

87. Deniger, D. C., A. A. Kolokoltsov, A. C. Moore, T. B. Albrecht, and R. A. Davey (2006) Targeting and penetration of virus receptor bearing cells by nanoparticles coated with envelope proteins of Moloney murine leukemia virus. Nano Lett. 6: 2414-2421.

88. Russell, S. J., K. W. Peng, and J. C. Bell (2012) Oncolytic virotherapy. Nat. Biotechnol. 30: 658-670.
89. Kaiser, C. R., M. L. Flenniken, E. Gillitzer, A. L. Harmsen, A. G. Harmsen, M. A. Jutila, T. Douglas, and M. J. Young (2007) Biodistribution studies of protein cage nanoparticles demonstrate broad tissue distribution and rapid clearance in vivo. Int. J. Nanomed. 2: 715-733.

90. Le, D. H. T., E. Méndez-López, C. Wang, U. Commandeur, M. A. randa, and N. F. Steinmetz (2018) Biodistribution of filamentous plant virus nanoparticles: pepino mosaic virus versus potato virus X. Biomacromolecules. 20: 469-477.

91. Beatty, P. H. and J. D. Lewis (2019) Cowpea mosaic virus nanoparticles for cancer imaging and therapy. Adv. Drug Deliv. Rev. 145: 130-144.

92. Lam, P., R. D. Lin, and N. F. Steinmetz (2018) Delivery of mitoxantrone using a plant virus-based nanoparticle for the treatment of glioblastomas. J. Mater. Chem. B. 6: 5888-5895.

93. Shukla, S., M. Jandzinski, C. Wang, X. Gong, K. W. Bonk, R. A. Keri, and N. F. Steinmetz (2019) A viral nanoparticle cancer vaccine delays tumor progression and prolongs survival in a HER2 ${ }^{+}$tumor mouse model. Adv. Ther. 2: 1800139.

94. Culver, J. N., A. D. Brown, F. Zang, M. Gnerlich, K. Gerasopoulos, and R. Ghodssi (2015) Plant virus directed fabrication of nanoscale materials and devices. Virology. 479-480: 200-212.

95. Barwal, I., R. Kumar, S. Kateriya, A. K. Dinda, and S. C. Yadav (2016) Targeted delivery system for cancer cells consist of multiple ligands conjugated genetically modified CCMV capsid on doxorubicin GNPs complex. Sci. Rep. 6: 37096.

96. Wu, Y., J. Li, H. Yang, J. Seoung, H. D. Lim, G. J. Kim, and H. J. Shin (2017) Targeted cowpea chlorotic mottle virus-based nanoparticles with tumor-homing peptide F3 for photothermal therapy. Biotechnol. Bioprocess Eng. 22: 700-708.

97. Shimizu, T., W. Ding, and N. Kameta (2020) Soft-matter nanotubes: A platform for diverse functions and applications. Chem. Rev. 120: 2347-2407.

98. Vernekar, G. Berger, A. E. Czapar, F. A. Veliz, D. I. Wang, N. F. Steinmetz, and S. J. Lippard (2018) Speciation of phenanthriplatin and its analogs in the core of tobacco mosaic virus. J. Am. Chem. Soc. 140: 4279-4287.

99. Franke, C. E., A. E. Czapar, R. B. Patel, and N. F. Steinmetz (2018) Tobacco mosaic virus-delivered cisplatin restores efficacy in platinum-resistant ovarian cancer cells. Mol. Pharm. 15: 29222931.

100. Chariou, P. L., K. L. Lee, A. M. Wen, N. M. Gulati, P. L. Stewart, and N. F. Steinmetz (2015) Detection and imaging of aggressive cancer cells using an epidermal growth factor receptor (EGFR)-targeted filamentous plant virus-based nanoparticle. Bioconjugate Chem. 26: 262-269.

101. Esfandiari, N., M. K. Arzanani, M. Soleimani, M. Kohi-Habibi, and W. E. Svendsen (2016) A new application of plant virus nanoparticles as drug delivery in breast cancer. Tumor Biol. 37: 1229-1236.

102. Ashley, C. E., E. C. Carnes, G. K. Phillips, P. N. Durfee, M. D. Buley, C. A. Lino, D. P. Padilla, B. Phillips, M. B. Carter, C. L. Willman, C. J. Brinker, J. do Carmo Caldeira, B. Chackerian, W. Wharton, and D. S. Peabody (2011) Cell-specific delivery of diverse cargos by bacteriophage MS2 virus-like particles. $A C S$ Nano. 5: 5729-5745.

103. Kolesanova, E. F., M. V. Melnikova, T. N. Bolshakova, E. Y. Rybalkina, and I. G. Sivov (2019) Bacteriophage MS2 as a tool for targeted delivery in solid tumor chemotherapy. Acta Naturae. 11: $98-101$.

104. Rhee, J. K., M. Hovlid, J. D. Fiedler, S. D. Brown, F. Manzenrieder, H. Kitagishi, C. Nycholat, J. C. Paulson, and M. G. Finn (2011) Colorful virus-like particles: fluorescent protein packaging by the Q $\beta$ capsid. Biomacromolecules. 12: 3977-3981.

105. Uchida, M., M. T. Klem, M. Allen, P. Suci, M. Flenniken, E. Gillitzer, Z. Varpness, L. O. Liepold, M. Young, and T. Douglas 
(2007) Biological containers: protein cages as multifunctional nanoplatforms. Adv. Mater. 19: 1025-1042.

106. Flenniken, M. L., D. A. Willits, A. L. Harmsen, L. O. Liepold, A. G. Harmsen, M. J. Young, and T. Douglas (2006) Melanoma and lymphocyte cell-specific targeting incorporated into a heat shock protein cage architecture. Chem. Biol. 13: 161-170.

107. Flenniken, M. L., L. O. Liepold, B. E. Crowley, D. A. Willits, M. J. Young, and T. Douglas (2005) Selective attachment and release of a chemotherapeutic agent from the interior of a protein cage architecture. Chem. Commun. 4: 447-449.

108. Wang, Z., C. Li, M. Ellenburg, E. Soistman, J. Ruble, B. Wright, J. X. Ho, and D. C. Carter (2006) Structure of human ferritin L chain. Acta Crystallogr. D Biol. Crystallogr. 62: 800-806.

109. Kanekiyo, M., W. Bu, M. G. Joyce, G. Meng, J. R. R. Whittle, U. Baxa, T. Yamamoto, S. Narpala, J. P. Todd, S. S. Rao, A. B. McDermott, R. A. Koup, M. G. Rossmann, J. R. Mascola, B. S. Graham, J. I. Cohen, and G. J. Nabel (2015) Rational design of an Epstein-Barr virus vaccine targeting the receptor-binding site. Cell. 162: 1090-1100.

110. Ghosh, S., S. Mohapatra, A. Thomas, D. Bhunia, A. Saha, G. Das, B. Jana, and S. Ghosh (2016) Apoferritin nanocage delivers combination of microtubule and nucleus targeting anticancer drugs. ACS Appl. Mater. Interfaces. 8: 30824-30832.

111. Huang, Y., Y. Luo, W. Zheng, and T. Chen (2014) Rational design of cancer-targeted BSA protein nanoparticles as radiosensitizer to overcome cancer radioresistance. ACS Appl. Mater. Interfaces. 6: 19217-19228.

112. Moon, H., J. Lee, J. Min, and S. Kang (2014) Developing genetically engineered encapsulin protein cage nanoparticles as a targeted delivery nanoplatform. Biomacromolecules. 15: 37943801.

113. Ren, D., F. Kratz, and S. W. Wang (2013) Engineered drugprotein nanoparticle complexes for folate receptor targeting. Biochem. Eng. J. 89: 33-41.

114. Barreto, J. A., W. O'Malley, M. Kubeil, B. Graham, H. Stephan, and L. Spiccia (2011) Nanomaterials: applications in cancer imaging and therapy. Adv. Mater. 23: H18-H40.

115. Park, K., S. Lee, E. Kang, K. Kim, K. Choi, and I. C. Kwon (2009) New generation of multifunctional nanoparticles for cancer imaging and therapy. Adv. Funct. Mater. 19: 1553-1566.

116. Choi, K. Y., G. Liu, S. Lee, and X. Chen (2012) Theranostic nanoplatforms for simultaneous cancer imaging and therapy: current approaches and future perspectives. Nanoscale. 4: 330342.

117. Yu, M. K., J. Park, and S. Jon (2012) Targeting strategies for multifunctional nanoparticles in cancer imaging and therapy. Theranostics. 2: 3-44.

118. Datta, A., J. M. Hooker, M. Botta, M. B. Francis, S. Aime, and K. N. Raymond (2008) High relaxivity gadolinium hydroxypyridonate-viral capsid conjugates: Nanosized MRI contrast agents. J. Am. Chem. Soc. 130: 2546-2552.

119. Le, D. H. T., H. Hu, U. Commandeur, and N. F. Steinmetz (2017) Chemical addressability of potato virus $\mathrm{X}$ for its applications in bio/nanotechnology. J. Struct. Biol. 200: 360-368.

120. Hu, H., Y. Zhang, S. Shukla, Y. Gu, X. Yu, and N. F. Steinmetz (2017) Dysprosium-modified tobacco mosaic virus nanoparticles for ultra-high-field magnetic resonance and near-infrared fluorescence imaging of prostate cancer. ACS Nano. 11: 92499258.

121. Hooker, J. M., J. P. O'Neil, D. W. Romanini, S. E. Taylor, and M. B. Francis (2008) Genome-free viral capsids as carriers for positron emission tomography radiolabels. Mol. Imaging Biol. 10: $182-191$

122. Lewis, J. D., G. Destito, A. Zijlstra, M. J. Gonzalez, J. P. Quigley, M. Manchester, and H. Stuhlmann (2006) Viral nanoparticles as tools for intravital vascular imaging. Nat. Med. 12: 354-360.
123. Woods, N. B., V. Bottero, M. Schmidt, C.von Kalle, and I. M. Verma (2006) Gene therapy: therapeutic gene causing lymphoma. Nature. 440: 1123.

124. Wang, Z., G. Liu, H. Zheng, and X. Chen (2014) Rigid nanoparticle-based delivery of anti-cancer siRNA: challenges and opportunities. Biotechnol. Adv. 32: 831-843.

125. Maggio, I., M. Holkers, J. Liu, J. M. Janssen, X. Chen, and M. A. Gonçalves (2014) Adenoviral vector delivery of RNAguided CRISPR/Cas9 nuclease complexes induces targeted mutagenesis in a diverse array of human cells. Sci. Rep. 4: 5105.

126. Li, H., C. Sheng, H. Liu, S. Wang, J. Zhao, L. Yang, L. Jia, P. Li, L. Wang, J. Xie, D. Xu, Y. Sun, S. Qiu, and H. Song (2018) Inhibition of HBV expression in HBV transgenic mice using AAV-delivered CRISPR-SaCas9. Front. Immunol. 9: 2080.

127. Yin, H., C. Q. Song, J. R. Dorkin, L. J. Zhu, Y. Li, Q. Wu, A. Park, J. Yang, S. Suresh, A. Bizhanova, A. Gupta, M. F. Bolukbasi, S. Walsh, R. L. Bogorad, G. Gao, Z. Weng, Y. Dong, V. Koteliansky, S. A. Wolfe, R. Langer, W. Xue, and D. G. Anderson (2016) Therapeutic genome editing by combined viral and non-viral delivery of CRISPR system components in vivo. Nat. Biotechnol. 34: 328-333.

128. Kay, M. A., J. C. Glorioso, and L. Naldini (2001) Viral vectors for gene therapy: the art of turning infectious agents into vehicles of therapeutics. Nat. Med. 7: 33-40.

129. Burton, E. A. and J. C. Glorioso (2000) Herpes simplex virus vector-based gene therapy for malignant glioma. Gene Ther. Mol. Biol. 5: 131-145.

130. Roehm, P. C., M. Shekarabi, H. S. Wollebo, A. Bellizzi, L. He, J. Salkind, and K. Khalili (2016) Inhibition of HSV-1 replication by gene editing strategy. Sci. Rep. 6: 23146.

131. Lin, C., H. Li, M. Hao, D. Xiong, Y. Luo, C. Huang, Q. Yuan, J. Zhang, and N. Xia (2016) Increasing the efficiency of CRISPR/ Cas9-mediated precise genome editing of HSV-1 virus in human cells. Sci. Rep. 6: 34531.

132. Allen, T. M. and P. R. Cullis (2004) Drug delivery systems: entering the mainstream. Science. 303: 1818-1822.

133. Emerich, D. F. and C. G. Thanos (2006) The pinpoint promise of nanoparticle-based drug delivery and molecular diagnosis. Biomol. Eng. 23: 171-184.

134. Jain, A. and S. K. Jain (2008) PEGylation: an approach for drug delivery. A review. Crit. Rev. Ther. Drug Carrier Syst. 25: 403447.

135. Steinmetz, N. F. and M. Manchester (2009) PEGylated viral nanoparticles for biomedicine: the impact of PEG chain length on VNP cell interactions in vitro and ex vivo. Biomacromolecules. 10: 784-792.

136. Steinmetz, N. F., M. E. Mertens, R. E. Taurog, J. E. Johnson, U. Commandeur, R. Fischer, and M. Manchester (2009) Potato virus $\mathrm{X}$ as a novel platform for potential biomedical applications. Nano Lett. 10: 305-312.

137. Bruckman, M. A., G. Kaur, L. A. Lee, F. Xie, J. Sepulveda, R. Breitenkamp, X. Zhang, M. Joralemon, T. P. Russell, T. Emrick, and Q. Wang (2008) Surface modification of tobacco mosaic virus with "click" chemistry. Chembiochem. 9: 519-523.

138. Mikkila, J., A. P. Eskelinen, E. H. Niemelä, V. Linko, M. J. Frilander, P. Törmä, and M. A. Kostiainen (2014) Virusencapsulated DNA origami nanostructures for cellular delivery. Nano Lett. 14: 2196-2200.

139. Lupia, T., S. Scabini, S. M. Pinna, G. Di Perri, F. G. De Rosa, and S. Corcione (2020) 2019 novel coronavirus (2019-nCoV) outbreak: A new challenge. J. Glob. Antimicrob. Resist. 21: 22-27.

140. Carter, D. C., B. Wright, W. G. Jerome, J. P. Rose, and E. Wilson (2020) A unique protein self-assembling nanoparticle with significant advantages in vaccine development and production. J. Nanomater. 2020: 4297937.

141. Mohsen, M. O., D. E. Speiser, A. Knuth, and M. F. Bachmann 
(2020) Virus-like particles for vaccination against cancer. Wiley Interdiscip. Rev. Nanomed. Nanobiotechnol. 12: e1579.

142. Zhai, L., R. Yadav, N. K. Kunda, D. Anderson, E. Bruckner, E. K. Miller, R. Basu, P. Muttil, and E. Tumban (2019) Oral immunization with bacteriophage MS2-L2 VLPs protects against oral and genital infection with multiple HPV types associated with head \& neck cancers and cervical cancer. Antiviral Res. 166: 56-65.

143. Speiser, D. E., K. Schwarz, P. Baumgaertner, V. Manolova, E. Devevre, W. Sterry, P. Walden, A. Zippelius, K. B. Conzett, G. Senti, V. Voelter, J. P. Cerottini, D. Guggisberg, J. Willers, C. Geldhof, P. Romero, T. Kündig, A. Knuth, R. Dummer, U. Trefzer, and M. F. Bachmann (2010) Memory and effector CD8 T-cell responses after nanoparticle vaccination of melanoma patients. J. Immunother. 33: 848-858.

144. Cai, H., S. Shukla, C. Wang, H. Masarapu, and N. F. Steinmetz (2019) Heterologous prime-boost enhances the antitumor immune response elicited by plant-virus-based cancer vaccine.
J. Am. Chem. Soc. 141: 6509-6518.

145. Gomes, A. C., M. Mohsen, and M. F. Bachmann (2017) Harnessing nanoparticles for immunomodulation and vaccines. Vaccines. 5: 6.

146. Schwarz, B. and T. Douglas (2015) Development of virus-like particles for diagnostic and prophylactic biomedical applications. Wiley Interdiscip. Rev. Nanomed. Nanobiotechnol. 7: 722-735.

147. Mohsen, M. O., A. C. Gomes, M. Vogel, and M. F. Bachmann (2018) Interaction of viral capsid-derived virus-like particles (VLPs) with the innate immune system. Vaccines. 6: 37.

148. Chen, D. S., Y. Q. Wu, W. Zhang, S. J. Jiang, and S. Z. Chen (2016) Horizontal gene transfer events reshape the global landscape of arm race between viruses and homo sapiens. Sci. Rep. 6: 26934.

149. Kotterman, M. A., T. W. Chalberg, and D. V. Schaffer (2015) Viral vectors for gene therapy: translational and clinical outlook. Annu. Rev. Biomed. Eng. 17: 63-89.

Publisher's Note Springer Nature remains neutral with regard to jurisdictional claims in published maps and institutional affiliations. 